\title{
ETHzürich
}

ETH Library

\section{Influence of crystal size and probe molecule on diffusion in hierarchical ZSM-5 zeolites prepared by desilication}

\section{Journal Article}

Author(s):

Meunier, Frederic C.; Verboekend, Danny; Gilson, Jean-Pierre; Groen, Johan C.; Pérez-Ramírez, Javier

Publication date:

2012-01-15

Permanent link:

https://doi.org/10.3929/ethz-a-010788848

Rights / license:

In Copyright - Non-Commercial Use Permitted

Originally published in:

Microporous and Mesoporous Materials 148(1), https://doi.org/10.1016/j.micromeso.2011.08.002

Funding acknowledgement:

134572 - A fundamental approach to the scale up of hierarchical zeolite catalysts (SNF) 


\section{Influence of crystal size and probe molecule on diffusion in}

\section{2 hierarchical ZSM-5 zeolites prepared by desilication}

3

$4 \quad$ Frederic C. Meunier*a, Danny Verboekend ${ }^{b}$, Jean-Pierre Gilson ${ }^{a}$, Johan C. Groen ${ }^{c}$

5 and Javier Pérez-Ramírez*b

$6{ }^{a}$ Laboratoire Catalyse et Spectrochimie, ENSICAEN, University of Caen, CNRS, 6 Bd

7 Maréchal Juin, 14050, Caen, France.

$8 \quad{ }^{b}$ Institute for Chemical and Bioengineering, Department of Chemistry and Applied

9 Biosciences, ETH Zurich, Wolfgang-Pauli-Strasse 10, HCI E 125, CH-8093, Zurich,

10 Switzerland.

11 'Delft Solids Solutions, B.V., Rotterdamseweg 183C, 2629 HD Delft, The Netherlands.

12 * Corresponding authors: E-mail (FCM): frederic.meunier@ensicaen.fr; E-mail (JPR):

13 jpr@chem.ethz.ch

Address for correspondence:

18 Dr Frederic C. Meunier

19 Laboratoire Catalyse et Spectrochimie

20 CNRS - University of Caen - ENSICAEN

216 Boulevard du Marechal Juin

2214050 Caen Cedex, France

23 Phone: + 33 (0) 231452731

24 Fax: +33 (0) 231452822

25 E-mail: frederic.meunier@ensicaen.fr 


\section{Abstract}

27 The improvement of molecular transport properties of hierarchical H-ZSM-5 obtained by desilication was evidenced by studying the desorption of $o$-xylene and isooctane by in situ diffuse reflectance infrared Fourier transform spectroscopy (DRIFTS). This technique enabled monitoring simultaneously bands associated with the molecular probes and the zeolite, using powdered sample masses as low as $1 \mathrm{mg}$. Two H-ZSM-5 samples with markedly different crystal sizes and shapes were investigated. The first sample was commercial and consisted of small crystallites (ca. $250 \mathrm{~nm})$. The second sample were laboratory-made large crystals with coffin-like shape $\left(c a .17 \times 4 \times 4 \mu \mathrm{m}^{3}\right)$. The hierarchical derivatives of the small and large zeolite crystals displayed 250 and $120 \mathrm{~m}^{2} \mathrm{~g}^{-1}$ of mesopore surface area, respectively, in contrast to the 62 and $5 \mathrm{~m}^{2} \mathrm{~g}^{-1}$ of the parent counterparts. The data based on $o$-xylene desorption were partly disguised by site-desorption limitations. Desorption experiments using isooctane evidenced a 4-fold reduction in the characteristic diffusion path length on both mesoporous small and large zeolites with respect to their purely microporous analogues. These results confirm the substantial potential for improvement of commercial nanocrystalline zeolites in diffusion-limited reactions upon the introduction of intra-crystalline mesoporosity by post-synthesis modification.

Keywords: Hierarchical zeolites; H-ZSM-5; Desilication; Diffusion; Isooctane; oxylene; Infrared spectroscopy. 


\section{Introduction}

49

Zeolites are microporous aluminosilicates extensively applied in industrial catalytic and adsorption/separation processes [1,2]. The intrinsic microporosity of these solids often imposes molecular diffusion limitations due to hindered access and slow intracrystalline transport. This leads to a substantial under-utilization of the potential of zeolites in catalytic applications by limiting the corresponding activity, selectivity, and catalyst lifetime [3]. Hierarchical (or mesoporous) zeolites can alleviate these issues by adding to the native microporosity an auxiliary network of inter- and/or intra-crystalline mesopores. The added mesoporosity increases the number of accessible micropores and effectively shortens the average path length to the active sites, hereby increasing their catalytic performance [4-7]. A wide variety of methods are available to prepare mesoporous zeolites [4,8-11]; those involve either the alteration of the synthesis protocol (bottom-up) or the post-synthetic modification of conventionally prepared zeolites (top-down). Controlled silicon leaching in alkaline media, known as desilication, belongs to the latter category and is widely applied due to a combination of simplicity, versatility, and efficiency [12,13].

Beneficial effects of hierarchical zeolites have been reported for a wide range of catalyzed reactions and often assigned automatically to improved transport or reduced diffusion constraints. However, the number of studies additionally reporting diffusion data is rather limited [4,7]. One should therefore carefully consider whether the catalytic benefits in hierarchical zeolites can be solely attributed to the introduction of mesoporosity, since other parameters such as the chemical composition, the acid site distribution or the number of defects may be also affected in the mesopore formation process [13-17]. As a matter of fact, Kortunov et al. [18] studied the diffusion of $n$ - 
octane and 1,3,5-triisopropylbenzene in zeolite $\mathrm{Y}$ and the mesoporous derivative prepared by steaming [5] (ultra-stable Y, USY) and concluded that, in this particular case, steaming did not significantly affect intra-crystalline diffusion probably because the created mesopores were not interconnected with the native micropores. De Jong and co-workers had earlier shown by 3D-TEM analysis that mesopores were occluded within the USY crystals and not accessible from the external surface [19].

Improved diffusion properties have been reported in the case of hierarchical zeolites with interconnected mesopores. Groen et al. [20] and Zhao et al. [21] measured the rates of uptake of neopentane and cumene, respectively, in microporous and hierarchical ZSM-5 zeolites. Both authors reported uptake rates 2-3 orders of magnitude higher for the hierarchical samples. Cho et al. [22] measured the uptake of Xe in hierarchical LTA zeolites and showed that the diffusivity increased linearly with the degree of mesoporosity in the samples. Other studies [23-26] have also reported increased desorption rates of probe molecules (isobutane, neopentane, butane, and propane) over hierarchical zeolites versus conventional zeolites.

Diffusion studies have traditionally focused on purely microporous and carefully grown (large) crystals [27-31]. Yet, small crystals $(<1 \mu \mathrm{m})$ should be also used to establish that improved transport could be attained on industrially relevant zeolites. To our knowledge, no direct comparison of the improvements in the transport property upon introduction of mesoporosity is available for both large and small (commercial) zeolite crystals of the same structure.

The present work reports an investigation on the diffusion in hierarchical zeolites of very different crystal sizes obtained by desilication. ZSM-5 was primarily selected because of its relevance in industrial catalysis [2]. Small ( $<1 \mu$ m diameter, noted “SP”) 
and large $\left(17 \times 4 \times 4 \mu \mathrm{m}^{3}\right.$, noted "LP”) ZSM-5 crystals and the hierarchical derivatives obtained by alkaline treatment (noted "SAT" and "LAT", respectively) were investigated. Examining both small and large crystals is worthwhile because large crystals are often used as model systems exhibiting reasonably well-defined geometric forms and sizes, while small crystals are of more practical importance. The specific parent and alkaline-treated zeolite samples have been extensively characterized in previous studies $[16,20]$. The desorption of o-xylene and isooctane (i.e. 2,2,4trimethylpentane, also noted iC8), which both exhibit a kinetic diameter larger than the H-ZSM-5 pore size, was monitored. This approach may limit the influence pore entrance effects as described by Reitmeier et al. [32] and make the diffusion of the sorbate through the pores the transport-limiting step, leading to an unambiguous assessment of the improvement related to the introduction of mesoporosity.

\section{Experimental}

\subsection{Materials and characterization}

The parent small crystals (SP) were obtained by calcination of a commercial $\mathrm{NH}_{4}-\mathrm{ZSM}$ 5 (Zeolyst, CBV 8014, measured Si/Al ratio $=47$ ) in static air at $823 \mathrm{~K}$ for $5 \mathrm{~h}$ using a heating rate of $5 \mathrm{~K} \mathrm{~min}^{-1}$. The corresponding hierarchical H-ZSM-5 sample (SAT) was obtained by an alkaline treatment in $0.2 \mathrm{M}$ of $\mathrm{NaOH}$ at $338 \mathrm{~K}$ for $30 \mathrm{~min}$, followed by three consecutive ion exchanges in $0.1 \mathrm{M} \mathrm{NH}_{4} \mathrm{NO}_{3}$ and calcination [16]. The large ZSM-5 crystals (LP), featuring a Si/Al $=30$, were synthesized as described elsewhere [20]. Applying the recipe given in this reference, the hierarchical sample (LAT) was prepared by an alkaline treatment in $0.2 \mathrm{M}$ of $\mathrm{NaOH}$ at $338 \mathrm{~K}$ for $120 \mathrm{~min}$, followed by ion exchange with $\mathrm{NH}_{4} \mathrm{NO}_{3}$ and calcination. 

optical emission spectroscopy (ICP-OES) (Perkin-Elmer Optima 3200RL (radial)). $\mathrm{N}_{2}$ isotherms at $77 \mathrm{~K}$ were measured with a Quantachrome Quadrasorb-SI gas adsorption analyser. Prior to the measurement, the samples were degassed in vacuum at $573 \mathrm{~K}$ for $10 \mathrm{~h}$. The $t$-plot method was used to discriminate between micro- and mesoporosity [33]. The Brunauer-Emmett-Teller (BET) method [34] was applied to determine the total surface area $\left(\mathrm{S}_{\mathrm{BET}}\right)$, which is used for comparative purposes. The pore size distribution (PSD) was obtained by applying the Barret-Joyner-Halenda (BJH) model [35] to the adsorption branch of the isotherm.

\subsection{Desorption measurements}

Between 1 and $5 \mathrm{mg}$ of zeolite powder was deposited onto a SiC bed in the crucible of a high temperature-low pressure diffuse reflectance FTIR spectroscopy (DRIFTS) reaction cell from Spectra-Tech. The cell was placed in a Collector assembly from Spectra-Tech and fitted in a Nicolet Magna 550 FTIR spectrometer equipped with a MCT detector cooled with liquid nitrogen. A FTIR spectrum recorded over SiC was used as background. The DRIFTS spectra of the zeolites were plotted as log $1 / \mathrm{R}$, where $\mathrm{R}$ is the sample reflectance. The function $\log 1 / \mathrm{R}$ (= pseudo-absorbance) provides better linearity between band intensity against coverage than that given by the Kubelka-Munk function for strongly absorbing media, such as those based on oxides [36].

140 The reaction cell was modified to eliminate bed by-pass by inserting some PTFE tape between the ceramic crucible and the metallic base plate. The only difference with the cell modifications described in [37] is that a quartz wool plug was used in place of a metallic mesh to hold the sample bed. High-purity Ar or CO from Air Liquide was fed 
through low-volume heated stainless-steel lines to the cell and through saturators kept at $273 \mathrm{~K}$ to carry the vapor of the hydrocarbons. The samples were initially equilibrated under $1.0 \mathrm{vol} . \%$ isooctane or $0.18 \mathrm{vol} . \%$ o-xylene in Ar at $423 \mathrm{~K}$.

147 The contribution of gas-phase hydrocarbons to the DRIFTS signal was determined 148 from reference experiments using CO (an IR-sensitive gas) as the carrier gas. The gasphase spectrum of $\mathrm{CO}$ and the hydrocarbon mixture was measured at the exit of the DRIFTS cell in a transmission FTIR gas-cell (optical path length: $27 \mathrm{~cm}$ ) and was thereafter used to eliminate gas-phase signals from the overall DRIFTS signal. The contribution of the gas-phase signal of the hydrocarbon probes on the overall DRIFTS band intensity was shown to be lower than $10 \%$ in all cases.

154 A gas flow rate of $60 \mathrm{~cm}^{3} \mathrm{STP} \mathrm{min}^{-1}$ of pure Ar was used to purge the hydrocarbon 155 from the system during the desorption experiment. No differences in desorption rates samples (vide infra). 
measured over the same materials using an in situ quartz transmission IR cell fitted with $\mathrm{KBr}$ windows. This was achieved by carrying out titration-type experiments at room temperature over a zeolite wafer of known weight. The samples were first evacuated under secondary vacuum ( $\mathrm{P}<10^{-5}$ torr) at $523 \mathrm{~K}$ for $15 \mathrm{~min}$. The hydrocarbon signal normalized to the zeolite overtones bands (vide infra) was then monitored as a function of the number of calibrated pulses sent into the cell. The number of moles in each pulse was determined from the known volume of the injection chamber $\left(1.73 \mathrm{~cm}^{3}\right)$ and the pressure in the injection lines read on a Pfeiffer pressure gauge.

\subsection{Calculation of characteristic diffusion lengths and diffusivities}

The desorption curves plotted as a function of the square root of time were used to calculate the (non-steady-state) diffusivity $\mathrm{D}_{\mathrm{ns}}[38,39]$. The expression of $\mathrm{D}_{\mathrm{ns}}$ is given by equation 1 :

$$
\left.\mathrm{D}_{\mathrm{ns}}=\frac{\pi}{4} \cdot \mathrm{L}^{2} \cdot \text { slope }^{2} \quad \text { (eqn. } 1\right)
$$

where L is the characteristic diffusion length of the crystallite and "slope" is the initial slope of the desorption curve plotted as a function of the square root of time $[20,40]$. The characteristic diffusion length is usually taken as the ratio between the volume and external surface of the crystallite and is equal, in the case of a spherical particle, to a third of the particle radius $r$, so that eqn. 1 rearranges to:

$$
\left.\mathrm{D}_{\mathrm{ns}}=\frac{\pi}{36} \cdot \mathrm{r}^{2} \cdot \text { slope }^{2} \quad \text { (eqn. } 2\right)
$$

Note that these equations are equivalent to those reported by Muller et al. [30] and 
192 Groen et al. [20]. These $\mathrm{D}_{\mathrm{ns}}$ values are marred by the accumulation of hydrocarbons in 193 the sample, leading to the presence of effectively "immobile" molecules alongside the 194 mobile species [38]. The $\mathrm{D}_{\text {ns }}$ values must be corrected by an accumulation factor $\mathrm{h}$ [38] 195 to determine the steady-state diffusivity $\mathrm{D}_{\text {ss }}$ :

$$
\left.\mathrm{D}_{\mathrm{ss}}=\mathrm{h} \mathrm{D} \mathrm{ns}_{\mathrm{ns}}=\frac{\mathrm{C}_{\mathrm{T}}}{\mathrm{C}_{0}} \mathrm{D}_{\mathrm{ns}} \quad \text { (eqn. } 3\right)
$$

198

where $\mathrm{C}_{\mathrm{T}}\left(\mathrm{mol} \mathrm{m} \mathrm{m}^{-3}\right)$ is the total concentration of hydrocarbon in the zeolite and $\mathrm{C}_{0}$ 200 $\left.(\mathrm{mol} \mathrm{m})^{-3}\right)$ is the corresponding gas-phase concentration. Considering the sorbate as an ideal gas:

202

203

$$
\left.\mathrm{C}_{0}=\frac{\mathrm{P}}{\mathrm{R} \mathrm{T}} \quad \text { (eqn. } 4\right)
$$

204

205 where $\mathrm{P}(\mathrm{Pa})$ is the partial pressure of the sorbate, $\mathrm{R}=8.314 \mathrm{~J} \mathrm{~K}^{-1} \mathrm{~mol}^{-1}$, and $\mathrm{T}(\mathrm{K})$ is 206 the adsorption temperature. $\mathrm{C}_{\mathrm{T}}$ was determined via calibration curves as described in the 207 previous section.

208 The slope and the corresponding apparent $\mathrm{D}_{\text {ss }}$ values of the hierarchical $\mathrm{H}-\mathrm{ZSM}-5$ crystals (calculated assuming the same crystallite size or characteristic diffusion length, L) were significantly higher than those of the parent samples. It was yet assumed that

211 the true $D_{\text {ss }}$ was constant and that the experimental differences only arose from a 212 decreased size or characteristic diffusion length. The effective size and L values were therefore computed by imposing the same $\mathrm{D}_{\mathrm{ss}}$ as that measured on the parent crystals. 


\section{Results}

\subsection{Zeolites}

217 The SP sample with $\mathrm{Si} / \mathrm{Al}=47$ consisted of 2-3 $\mu$ m agglomerates made of $c a .250 \mathrm{~nm}$ 218 primary spherical crystallites (average size determined by TEM, data not shown). The

219 LP sample with $\mathrm{Si} / \mathrm{Al}=30$ consisted of large $\left(\right.$ ca. $\left.17 \times 4 \times 4 \mu \mathrm{m}^{3}\right)$ ZSM-5 crystals with coffin-like shape. Microscopy studies and further characterization of the starting zeolites can be found elsewhere (small crystals in [16] and large crystals in [20]). Treatment of ZSM-5 zeolites with $\mathrm{Si} / \mathrm{Al}=25-50$ in aqueous $\mathrm{NaOH}$ solutions under the conditions used in this work $(0.2 \mathrm{M}, 338 \mathrm{~K}, 30-120 \mathrm{~min})$ is known to generate extensive intracrystalline mesoporosity in the zeolites by selective extraction of framework silicon $[41,42]$. Due to this, the molar $\mathrm{Si} / \mathrm{Al}$ ratio of the samples decreased (Table 1 ). The development of mesoporosity is clearly observed by gas adsorption. Fig. 1 shows that the typical type I $\mathrm{N}_{2}$ isotherm in the purely microporous sample transforms into a combined I and IV isotherm in the $\mathrm{NaOH}$-treated sample, a known fingerprint of a hierarchical porous system [4]. The hierarchical derivatives of the small and large zeolite crystals displayed a mesopore surface area $\left(\mathrm{S}_{\text {meso }}\right)$ of 250 and $120 \mathrm{~m}^{2} \mathrm{~g}^{-1}$, respectively, in contrast to the values of 62 and $5 \mathrm{~m}^{2} \mathrm{~g}^{-1}$ for the parent counterparts (Table 1). As commonly reported, the hierarchical zeolites displayed an increased total pore volume $\left(\mathrm{V}_{\text {pore }}\right)$ and total surface area $\left(\mathrm{S}_{\mathrm{BET}}\right)$, while the micropore volume $\left(\mathrm{V}_{\text {micro }}\right)$ decreased. The mesopore size distribution was centered around $10 \mathrm{~nm}$ in both hierarchical samples (insets of Fig. 1). Additional characterization of these specific alkaline-treated zeolites $[16,20]$ is not elaborated here for the sake of conciseness. We can briefly highlight that the alkaline-treated samples maintain the long-range crystallinity of the parent zeolites (determined by X-ray diffraction) as well as the 
original micropore size (determined by high-resolution low-pressure Ar adsorption at $87 \mathrm{~K})$. Mercury porosimetry indicated that the $10 \mathrm{~nm}$ mesopores are accessible from the external surface of the crystal, that is, desilication does not generate occluded mesoporosity. In addition, the acidity properties $\left(\mathrm{NH}_{3}-\mathrm{TPD}\right.$ and infrared of pyridine and/or CO adsorbed) are largely preserved.

\subsection{Diffusion measurements}

The in situ DRIFTS spectra of the activated SP and SAT samples equilibrated under pure Ar, $178 \mathrm{~Pa}$ of $o$-xylene or $1 \mathrm{kPa}$ of isooctane are shown in Figs. 2a-b. The alkalinetreated sample exhibited a markedly higher proportion of terminal silanol groups (ca. $3740 \mathrm{~cm}^{-1}$ ), due to the higher external surface of this sample created by desilication. The adsorption of $o$-xylene (Fig. 2a) on both the SP and SAT materials was significantly stronger than that of isooctane (Fig. 2b), as evidenced by the significant decrease of the bridged hydroxyls band at $3600 \mathrm{~cm}^{-1}$ and the concomitant formation of H-bonded hydroxyls (broad band over 3600-3000 $\mathrm{cm}^{-1}$ ) observed in the case of $o$-xylene.

The rates of desorption of $o$-xylene and isooctane from SP and SAT were assessed. The desorption rate of $o$-xylene marginally increased in the case of SAT as compared to that of SP (Fig. 3, top). The corresponding characteristic diffusion length decreased by a factor 1.4 (calculated using an average crystal diameter of $250 \mathrm{~nm}$ for the parent zeolite). However, the improvement in desorption rate was markedly higher in the case of isooctane (Fig. 3, bottom), leading to a 3.6-fold shorter characteristic diffusion length.

This apparent discrepancy between the transport improvements of $o$-xylene and isooctane was rationalized by calculating the characteristic desorption time of these 
molecules from the surface sites using elementary kinetic theory [38]. Assuming sorption heats on H-ZSM-5 for $o$-xylene and isooctane of 120 and $100 \mathrm{~kJ} \mathrm{~mol}^{-1}[43,44]$, respectively, the corresponding desorption times should be about $65 \mathrm{~s}$ and less than $0.2 \mathrm{~s}$ at $428 \mathrm{~K}$. This indicates that $o$-xylene removal from the crystals was limited by both (i) the stochastic diffusion (Fickian) process and (ii) a site-desorption controlled molecular transport, while the latter constraint was negligible in the case of isooctane. Therefore, only the isooctane data can be used to determine the true decrease in characteristic diffusion length under the present experimental conditions.

The desorption of isooctane was also followed over the large H-ZSM-5 crystals.

272 Similarly to the case of the SP and SAT (Fig. 2b), iC8 only interacted weakly with the

273 Brønsted acid sites of LP and LAT (Fig. 2c). The desorption time of isooctane was markedly shorter over LAT than over LP (Fig. 4). The corresponding apparent decrease in characteristic diffusion length was about 3.9 (calculated using an average characteristic diffusion length of $0.8 \mu \mathrm{m}$ for the parent zeolite [20]).

277 It must be stressed that the isooctane concentration in SP, SAT, LP, and LAT were similar (Fig. 5). Therefore a similar amount of sorbate was removed in each case, allowing a direct comparison of the slope of the linear part of the desorption curves [45]. The initial desorption rate over LAT was similar or even faster than that observed over SP, indicating that the transport of sorbate in the mesoporous large crystal resembled that in the parent commercial H-ZSM-5. Note that the differences in the shape of the desorption curves were due to the fact that a different distribution of characteristic lengths were present in each case, making a detailed calculation of characteristic diffusion path length very difficult. 


\section{Discussion}

The present data highlights a remarkable improvement of the desorption rates of $o$ xylene and, even more clearly, of isooctane (Fig. 3) on hierarchical H-ZSM-5 obtained by controlled silicon dissolution in alkaline medium. The transport improvement was evidenced for both small commercial crystals and large H-ZSM-5 crystals (Fig. 4). While the nature of the sorbate and the experimental conditions can affect the nature of the step limiting the transport (vide infra), the crystallite size can also be determining. It has been proposed that intra-crystalline diffusion was limiting the uptake of benzene, toluene, and p-xylene over 3-4 $\mu \mathrm{m}$ ZSM-5 particles, while the uptake was controlled by surface barriers for particles smaller than $100 \mathrm{~nm}$ [46]. These observations stress the difficulty to compare data from various systems.

It must be noted that the in situ DRIFTS data collected in the present study were reproducible. The error on the value of the slope of the decaying signal of the desorbing hydrocarbon was found to be below $10 \%$. In summary, DRIFTS is a convenient investigative technique because it enables:

i. directly using a powder, and not a pressed wafer, in which additional transport limitation may occur,

ii. using sample masses as low as $1 \mathrm{mg}$ and a high flow rate of purge gas, which limit inter-crystalline re-adsorption

iii. monitoring simultaneously bands associated with the probes (gas phase and adsorbed) and with the zeolite, allowing quantitative analyses.

DRIFTS band intensities are essentially proportional to sorbate concentrations, providing pseudo-absorbance (and not Kubelka-Munk) units are used when sorbate reflectance is high, as is typically the case in studies pertaining to heterogeneous 
catalysts [36]. A limitation of DRIFTS is that only a fraction of the bed is probed [47]; this becomes negligible when sample beds are homogeneous and inter-crystalline readsorption is reduced by using very low sample amounts and high purge gas flow rate as in the present study.

315 The signal-to-noise ratio of the DRIFTS-based plots (Figs. 3 and 4) were clearly lower than that obtained for instance on a TEOM microbalance as described in [20]. This is a compromise that is usually acceptable, taken into account the cost and availability of DRIFTS equipment and the ease with which the data can be obtained. The lower accuracy of DRIFTS-based measurements could also explain the somewhat lower uptake of isooctane observed over SAT as compared to SP, LP and LAT (Fig. 5), although isooctane adsorption isotherms should be measured to ascertain this point. Diffusion studies carried out using different methods and experimental conditions have often led to diffusivity values varying by orders of magnitude [38,39,48]. Some of these discrepancies arise from confusions in the description of the state of the molecules present in the sorbent, a fraction (determined by thermodynamics) being immobilized, while the remaining part effectively participates to the molecular transport (with a given diffusivity $\mathrm{D}_{\mathrm{ss}}$ ) at any given time [38]. This problem is solved by correcting the apparent non-steady-state diffusivity $D_{n s}$ with the accumulation factor to obtain the $D_{\text {ss }}$ as described in the experimental section $[38,39]$. The desorption of $o$-xylene (kinetic diameter $=0.74 \mathrm{~nm}$ ) and isooctane (kinetic diameter $=0.62 \mathrm{~nm}$ ) was used in the present study. These molecules were chosen because those exhibit kinetic diameters larger than the crystallographic pore size of $\mathrm{H}$ ZSM-5 (ca. $0.56 \mathrm{~nm}$ ) and should make molecular transport through the MFI micropores the rate-determining step. 
Another difficulty plaguing diffusivity measurements is that the step limiting the transport may depend on the sorbate and experimental conditions. The comparison of the desorption curves of $o$-xylene and isooctane over SP and SAT (Fig. 3) and the associated characteristic desorption times [38] clearly evidenced such occurrence in the present case. The interaction of $o$-xylene was sufficiently strong with the Brønsted acid sites of the H-ZSM-5 (as evidenced by the formation of a large H-bonded hydroxyl band, Fig. 2.a) so that the site desorption time became significant (ca. $65 \mathrm{~s}$ ) in comparison to the timescale of the desorption experiment (more than $80 \%$ of $o$-xylene desorbed within $7 \mathrm{~min})$. The benefit of mesoporosity in the SAT sample was therefore limited, since the stochastic diffusion process throughout the hierarchical pore system became less dominant. Consequently, probe molecule selection is a vital aspect to measure true diffusion properties in zeolites.

The steady-state diffusivity of $o$-xylene calculated assuming a crystallite diameter for SP of $250 \mathrm{~nm}$ was $D_{\text {ss }}(S P$, average crystal size $250 \mathrm{~nm})=1.8 \times 10^{-10} \mathrm{~cm}^{2} \mathrm{~s}^{-1}$. This value is slightly smaller than that reported for highly siliceous H-ZSM-5 over identical experimental conditions [39], i.e. $D_{\mathrm{ss}}=2.5 \times 10^{-10} \mathrm{~cm}^{2} \mathrm{~s}^{-1}$. A lower apparent value of steady-state diffusivity for $o$-xylene was expected here, because of the higher acid site concentration of our samples that slowed down the diffusion of the sorbate.

The steady-state diffusivity of isooctane at $428 \mathrm{~K}$ calculated assuming a crystallite diameter for SP of $250 \mathrm{~nm}$ was $\mathrm{D}_{\mathrm{ss}}(\mathrm{SP}, 250 \mathrm{~nm})=2.4 \times 10^{-12} \mathrm{~cm}^{2} \mathrm{~s}^{-1}$, while the value calculated for the same molecule over the LP H-ZSM-5, assuming a characteristic diffusion length of $800 \mathrm{~nm}$ [20] was $D_{\mathrm{ss}}(\mathrm{LP}, \mathrm{L}=800 \mathrm{~nm})=77 \times 10^{-12} \mathrm{~cm}^{2} \mathrm{~s}^{-1}$. These values are expected to be equal and the 32-fold higher diffusivity measured for LP suggests that the average small crystal size and/or the characteristic diffusion length of 
359 the large crystal were badly estimated. We are not aware of any work reporting 360 isooctane diffusivity values over H-ZSM-5 under similar experimental conditions that 361 could help resolve this matter.

362 It is most likely that the characteristic diffusion length of the large crystal was much 363 smaller. A close analysis of the micrographs reported in [20] indicates that LP did not consist of single crystals but the particles were formed of intergrown units. One can therefore propose that the defects at the intergrowth could offer a low resistance to isooctane transport. Assuming that the true diffusivity of isooctane in $\mathrm{H}-\mathrm{ZSM}-5$ at $428 \mathrm{~K}$ was that measured in SP, i.e. $D_{\mathrm{ss}}=2.4 \times 10^{-12} \mathrm{~cm}^{2} \mathrm{~s}^{-1}$, then the effective characteristic diffusion length of LP should be $140 \mathrm{~nm}$ (and not $800 \mathrm{~nm}$ ).

Note that the characteristic diffusion length of a sphere is a third of its radius and therefore L $=42 \mathrm{~nm}$ for SP $(250 \mathrm{~nm})$. The characteristic lengths of SP and LP would therefore amount to 42 and $140 \mathrm{~nm}$, respectively. Whatever the true characteristic diffusion length of LP, the improvement of isooctane transport observed in the LAT remains the same and corresponds to a ca. 4-fold decrease of the diffusion path length.

374 The similar decrease of characteristic diffusion length observed over the small and large hierarchical crystals, i.e. factors 3.6 and 3.9, respectively, implied major structural changes. A more than 50-fold decrease of the volume of the effective elementary crystallite was achieved in the present case. The possibility to create mesoporous zeolites especially from small crystals by post-synthetic alkaline treatments is a major asset and further confirms the suitability of desilication for improving molecular transport over commercial catalysts. 
crystals. This is higher than our present observation over the same materials, i.e. an overall 4-fold decrease was observed. This discrepancy could be due to the differing experimental method (adsorption uptake in a TEOM microbalance) and probe molecule (neopentane). Moreover, no attempt was made here to deconvolute the decay signal because of the lower signal-to-noise ratio obtained with our IR based-data. This is also a reminder that the mesoporosity creation by desilication may not always be homogeneous through the zeolite, as described by Groen et al. [20].

Overall, our results support the view that the improved catalytic performance over commercial mesoporous zeolites [4,7] is largely due to improved transport, which has been unambiguously quantified in our study. Diffusion studies on large crystals can also have a practical relevance and serve as a guide, despite being model systems. Large zeolite crystals may sometimes offer the advantage of presenting better-defined sizes and shapes, although the presence of intergrowth should not be neglected and could decrease the actual characteristic diffusion length.

In addition, the characteristic diffusion lengths of reactants in hierarchical zeolites and their parents leads to an easy and quantitative measurement of the associated catalytic improvements when single file diffusion is not dominant [49-52], i.e. where the Thiele modulus can be used.

\section{Conclusions}

The present work demonstrates that a combination of DRIFTS and transmission FTIR can deliver accurate quantitative diffusivity values in a simple, cost-effective, and fast manner. The choice of the probe and experimental conditions are critical if the transport properties are to be free of site-desorption effects, as observed here in the case of $o$ - 
407

408

409

410

411

412

413

414

415

416

417

418

419

420

421

422

423

424

425

426

427

428

429

430

xylene. In the case of isooctane, a ca. 4-fold reduction in the characteristic diffusion path length of both submicron and large H-ZSM-5 crystals was observed. These results show that desilication is a highly efficient synthetic strategy to alleviate diffusion limitations in commercial zeolite catalysts (typically submicron crystals) by producing hierarchical samples to an extent comparable to that observed in the desilication of (model) large crystals.

\section{Acknowledgements}

ETH Zurich, the Swiss Science National Foundation (project number 200021-134572), the ANR (Hizecoke project, 2010 BLAN 723), and the Région Basse-Normandie are acknowledged for financial support.

\section{References}

[1] A. Corma, Chem. Rev., 95 (1995) 559.

[2] W. Vermeiren, J.-P. Gilson, Top. Catal., 52 (2009) 1131.

[3] A. Corma, Chem. Rev., 97 (1997) 2373.

[4] J. Pérez-Ramírez, C.H. Christensen, K. Egeblad, C.H. Christensen, J. C. Groen, Chem. Soc. Rev., 37 (2008) 2530.

[5] S. van Donk, A.H. Janssen, J.H. Bitter, K. P. de Jong, Catal. Rev. -Sci. Eng., 45 (2003) 297.

[6] R. Chal, C. Gerardin, M. Bulut, S. van Donk, ChemCatChem, 3 (2011) 67.

[7] M.S. Holm, E. Taarning, K. Egeblad, C.H. Christensen, Catal. Today, 168 (2011) 3.

[8] L. Tosheva, V. Valtchev, Chem. Mater., 17 (2005) 2494. 
[9] W.J. Roth, J. Čejka, Catal. Sci. Technol., 1 (2011) 43.

432 [10] J. Čejka, S. Mintova, Catal. Rev. -Sci. Eng., 49 (2007) 457.

433

[11] K. Egeblad, C.H. Christensen, M. Yu. Kustova, C. H. Christensen, Chem. Mater., 20 (2008) 946.

437

[12] J. C. Groen, L.A.A. Peffer, J.A. Moulijn, J. Pérez-Ramírez, J. Mater. Chem., 16 (2006) 2121.

[13] D. Verboekend and J. Pérez-Ramírez, Catal. Sci. Technol., 2011, doi: 10.1039/C1CY00150G.

[14] M.S. Holm, S. Svelle, F. Joensen, P. Beato, C.H. Christensen, S. Bordiga, M. Bjørgen, Appl. Catal. A: Gen., 356 (2009) 23.

[15] F. Thibault-Starzyk, I. Stan, S. Abelló, A. Bonilla, K. Thomas, C. Fernandez, J.-P. Gilson, J. Pérez-Ramírez, J. Catal., 264 (2009) 11.

[16] C. Fernandez, I. Stan, J.-P. Gilson, K. Thomas, A. Vicente, A. Bonilla and J. Pérez-Ramírez, Chem. Eur. J., 16 (2010) 6224.

[17] P. Sazama, B. Wichterlova, J. Dedecek, Z. Tvaruzkova, Z. Musilova, L. Palumbo, S. Sklenak, O. Gonsiorova, Microporous Mesoporous Mater., 143 (2011) 87.

[18] P. Kortunov, S. Vasenkov, J. Kärger, R. Valiullin, P. Gottschalk, M. F. Elía, M. Perez, M. Stöcker, B. Drescher, G. McElhiney, C. Berger, R. Gläser, J. Weitkamp, J. Am. Chem. Soc., 127 (2005) 13055.

[19] A.H. Janssen, A.J. Koster, K.P. de Jong, Ang. Chem. Int. Ed., 40 (2001) 1102.

[20] J.C. Groen, W. Zhu, S. Brouwer, S.J. Huynink, F. Kapteijn, J.A. Moulijn, J. PérezRamírez, J. Am. Chem. Soc., 129 (2007) 355.

[21] L. Zhao, B. Shen, J. Gao, J. Gao, C. Xu, J. Catal., 258 (2008) 228.

[22] K. Cho, H.S. Cho, L.-C. de Menorval, R. Ryoo, Chem. Mater., 21 (2009) 5664. 
[23] C.H. Christensen, K. Johannsen, E. Törnqvist, I. Schmidt, H. Tøpsoe, C.H. Christensen, Catal. Today, 128 (2007) 117.

[24] J. Pérez-Ramírez, D. Verboekend, A. Bonilla, S. Abelló, Adv. Funct. Mater., 19 (2009) 3972.

[25] D. Verboekend, J.C. Groen, J. Pérez-Ramírez, Adv. Funct. Mater., 20 (2010) 1441.

[26] D. Verboekend, R. Caicedo-Realpe, A. Bonilla, M. Santiago, J. Pérez-Ramírez, Chem. Mater., 22 (2010) 4679.

[27] L. Zhang, C. Chmelik, A.N.C. van Laak, J. Kärger, P.E. de Jongh, K.P. de Jong, Chem. Commun., (2009) 6424.

[28] P. Kortunov, C. Chmelik, J. Kärger, R.A. Rakoczy, D.M. Ruthven, Y. Traa, S. Vasenkov, J. Weitkamp, Adsorption, 11 (2005) 235.

[29] P. Kortunov, S. Vasenkov, C. Chmelik, J. Kärger, D.M. Ruthven, J. Wloch, Chem. Mater., 16 (2004) 3552.

[30] G. Muller, T. Narbeshuber, G. Mirth, J.A. Lercher, J. Phys. Chem., 98 (1994) 7436.

[31] M.H.F. Kox, E. Stavitski, J.C. Groen, J. Pérez-Ramírez, F. Kapteijn, B.M. Weckhuysen, Chem. Eur. J. 14 (2008) 1718.

[32] S.J. Reitmeier, O.C. Gobin, A. Jentys, J.A. Lercher, Angew. Chem. Int. Ed., 48 (2009) 533.

[33] B.C. Lippens, J.H. de Boer, J. Catal., 4 (1965) 319.

[34] S. Brunauer, P.H. Emmett, E. Teller, J. Am. Chem. Soc. 60 (1938) 309.

[35] E.P. Barrett, L.G. Joyner, P.P. Halenda, J. Am. Chem. Soc., 73 (1951) 373.

[36] J. Sirita, S. Phanichphant, F.C. Meunier, Anal. Chem., 79 (2007) 3912. 
[37] F.C. Meunier, A. Goguet, S. Shekhtman, D. Rooney, H. Daly, Appl. Catal. A, 340 (2008) 196.

[38] P.B. Weisz, Ind. Eng. Chem. Res., 34 (1995) 2692.

[39] S.F. Garcia, P.B. Weisz, J. Catal., 121 (1990) 294.

[40] F.C. Meunier, L. Domokos, K. Seshan, J.A. Lercher, J. Catal., 211 (2002) 366.

[41] J.C. Groen, L.A.A. Peffer, J.A. Moulijn, J. Pérez-Ramírez, Colloid Surface A, 241 (2004) 53.

[42] J.C. Groen, J.A. Moulijn, J. Pérez-Ramírez, Ind. Eng. Chem. Res., 46 (2007) 4193.

[43] Q. Huang, H. Vinh-Thang, A. Malekian, M. Eic, D. Trong-On, S. Kaliaguine, Microporous Mesoporous Mater., 87 (2006) 224.

[44] F. Eder, J.A. Lercher, Zeolites, 18 (1997) 75.

[45] If one of two crystals with identical pore structure and dimension would adsorbed ten times more molecules, then the corresponding desorption slope would be typically 10 -fold lower.

[46] O.C. Gobin, S.J. Reitmeier, A. Jentys, J.A. Lercher, J. Phys. Chem. C, 113 (2009) 20435.

[47] C. Mondelli, V. Dal Santo, A. Trovarelli, M. Boaro, A. Fusi, R. Psaro, S. Recchia, Catal. Today, 113 (2006) 81.

[48] J. Kärger, S. Vasenkov, Microporous Mesoporous Mater., 85 (2005) 195.

[49] W.O. Haag, R.M. Lago, P.B. Weisz, Faraday Discuss. Chem. Soc., 72 (1981) 317.

[50] N.Y. Chen, T.F. Degnan, C. Morris Smith, Molecular Transport and Reaction in Zeolites: Design and Application of Shape Selective Catalysis, John Wiley \& Sons Inc., 1994. 
503 [51] D.M. Ruthven, M.F.M. Post, in: H. van Bekkum, E.M. Flanigen, J.C. Jansen 504 (Eds.), Introduction to Zeolite Science and Practice, vol. 137, Elsevier, $505 \quad$ Amsterdam, 2001, pp. 525-578.

506 [52] S. van Donk, A. Broersma, O.L.J. Gijzeman, J.A. van Bokhoven, J.H. Bitter, K.P. 507 de Jong, J. Catal., 204 (2001) 272.

508 
510 Table 1. Composition and porosity of the H-ZSM-5 samples.

511

512

513

514

515

516

517

518

519

\begin{tabular}{|c|c|c|c|c|c|}
\hline Sample & & $\mathrm{V}_{\text {pore }} \mathrm{b} /$ & $\mathrm{V}_{\text {micro }}{ }^{\mathrm{c}} /$ & $\mathrm{V}_{\text {meso }} \mathrm{d} /$ & $\mathrm{S}_{\text {meso }} \mathrm{c} /$ \\
\hline
\end{tabular}

\begin{tabular}{lllllll}
\hline SP & 47 & 0.27 & 0.17 & 0.10 & 62 & 457
\end{tabular}

520

521

522

${ }^{a}$ ICP-OES

523

${ }^{\mathrm{b}}$ Volume of $\mathrm{N}_{2}$ adsorbed at $\mathrm{p} / \mathrm{p}_{0}=0.99$.

524

${ }^{\mathrm{c}} t$-plot.

525

${ }^{\mathrm{d}} \mathrm{V}_{\text {meso }}=\mathrm{V}_{\text {pore }}-\mathrm{V}_{\text {micro. }}$.

526 
Figure 1. $\mathrm{N}_{2}$ isotherms at $77 \mathrm{~K}$ and the thereof derived $\mathrm{BJH}$ adsorption pore size distributions (insets) for the parent small (SP, and the corresponding small (SAT, $\triangle$ ) and large (LAT, $O$ ) samples in mesoporous form.

533

534

Figure 2. DRIFTS spectra collected over the H-ZSM-5 crystals at 428 K. (a) SP and SAT under Ar or at equilibrium under $178 \mathrm{~Pa}$ of $o$-xylene, (b) SP and SAT under Ar or at equilibrium under $1 \mathrm{kPa}$ isooctane and (c) LP and LAT under Ar and at equilibrium under $1 \mathrm{kPa}$ isooctane.

538

539

Figure 3. Desorption of $o$-xylene and isooctane at $428 \mathrm{~K}$ from the commercial H-ZSM-

A) and mesoporous (SAT, $\triangle$ ) forms.

541

542 Figure 4. Desorption of isooctane at $428 \mathrm{~K}$ from the small and large H-ZSM-5 crystals in parent and mesoporous forms.

544

545

Figure 5. Equilibrium concentration of isooctane at $428 \mathrm{~K}$ over the H-ZSM-5 samples under $1 \mathrm{kPa}$ of isooctane (solid bars). The corresponding accumulation factor, i.e. the ratio of isooctane concentration in the sample to that in the gas phase, is also shown (open bars). 
550 Figure 1.

551

552

553

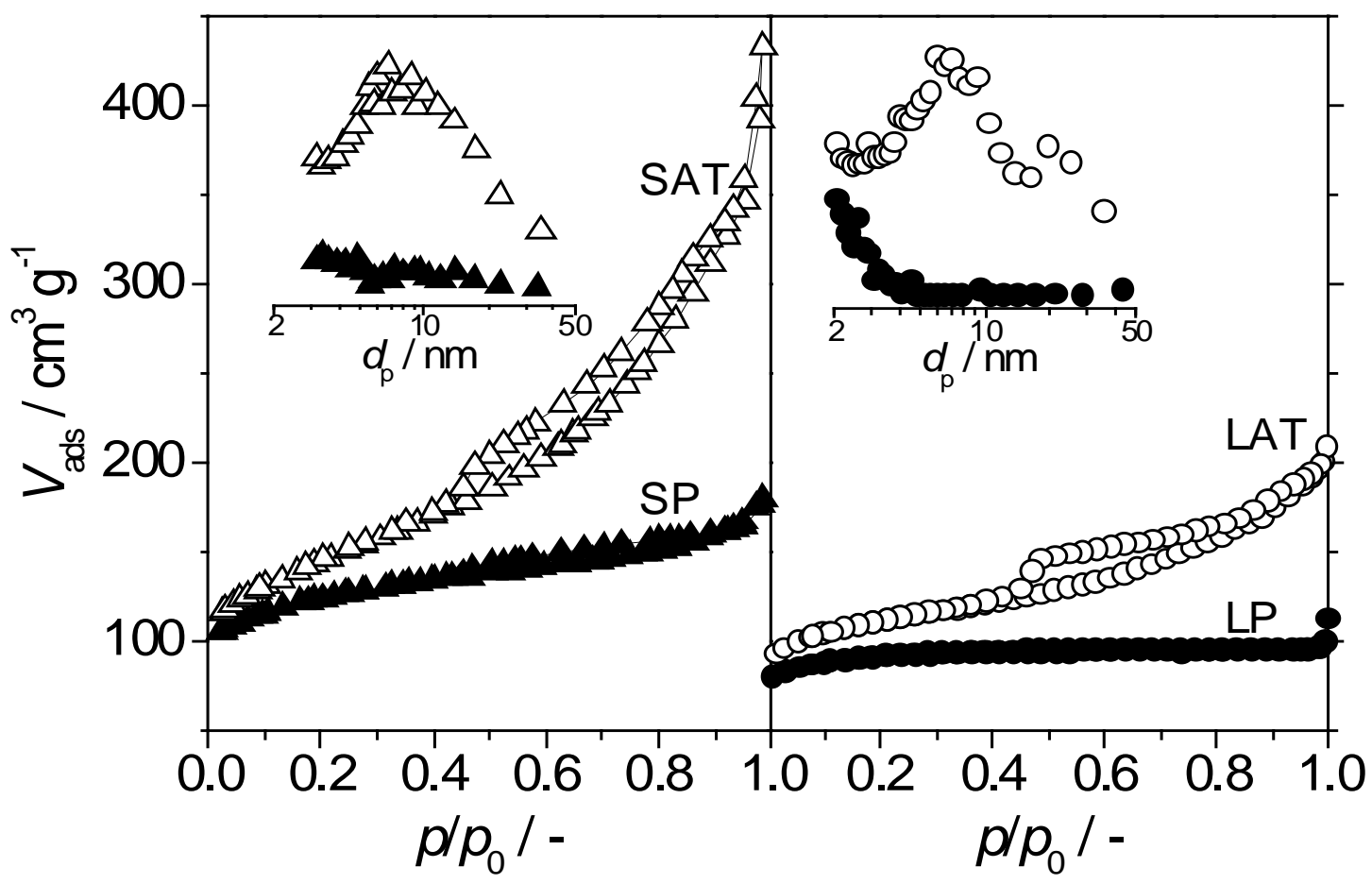

554 
Figure 2.

556

(a)

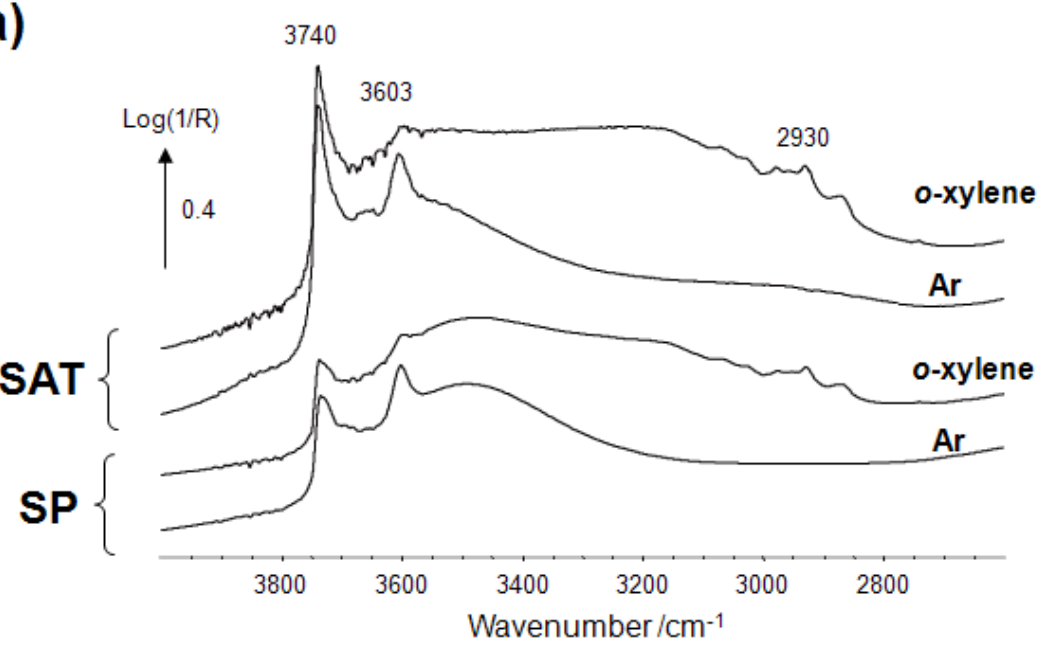

(b)

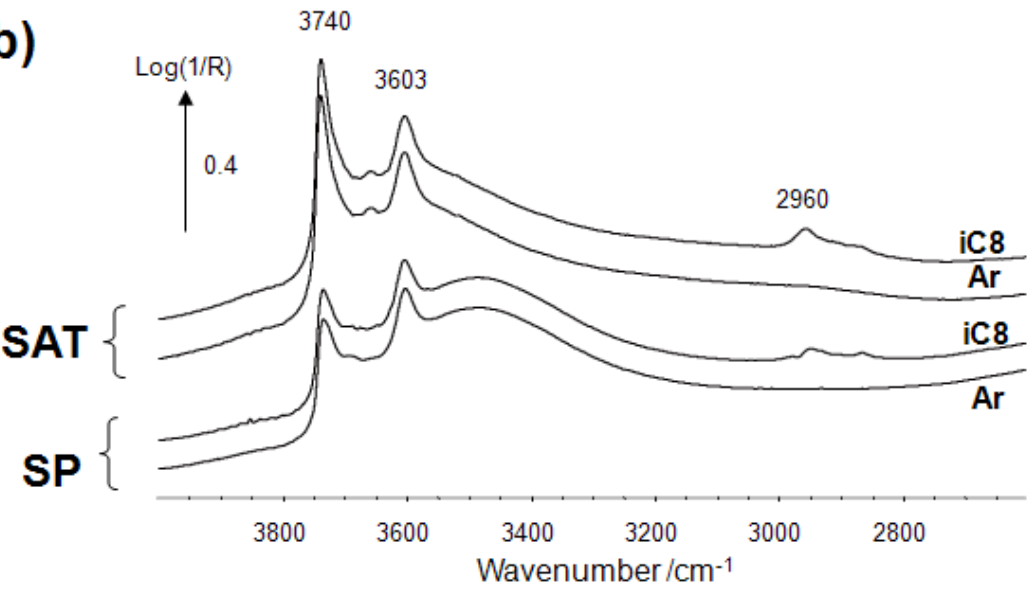

(c)

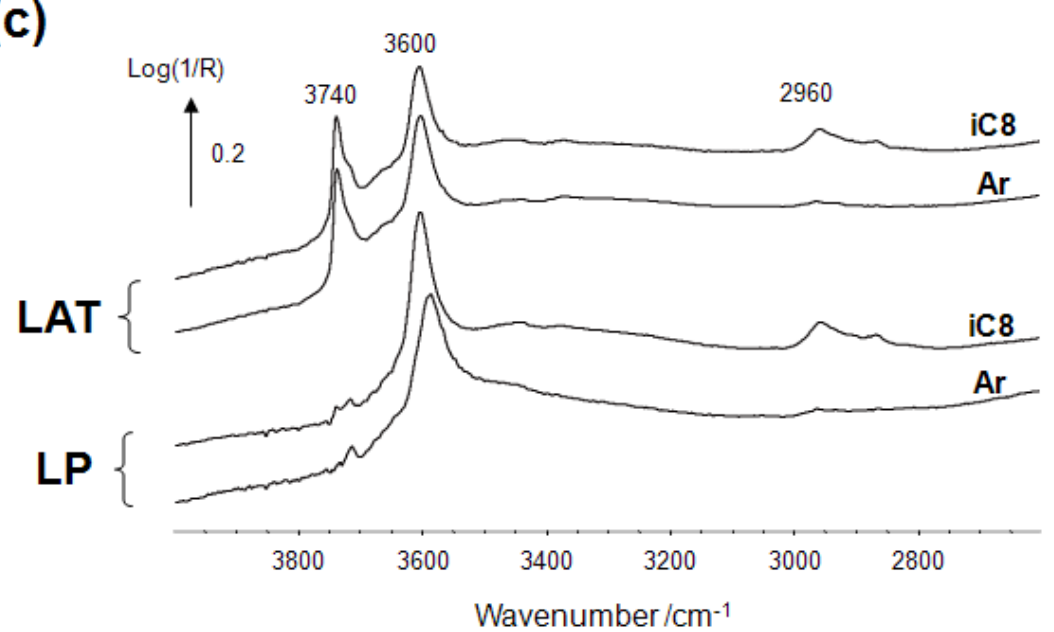


559 Figure 3.
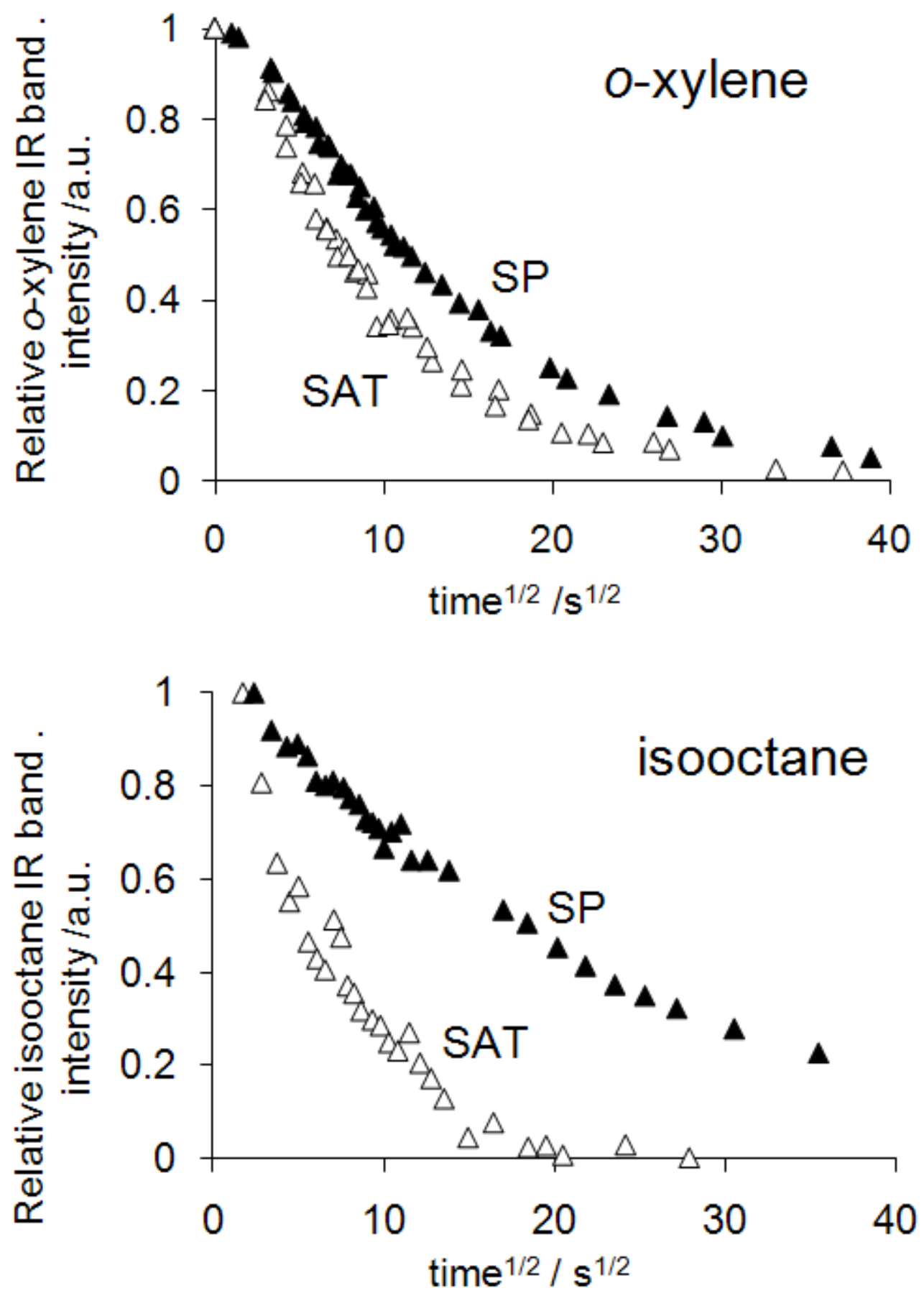
563 Figure 4.

564

565

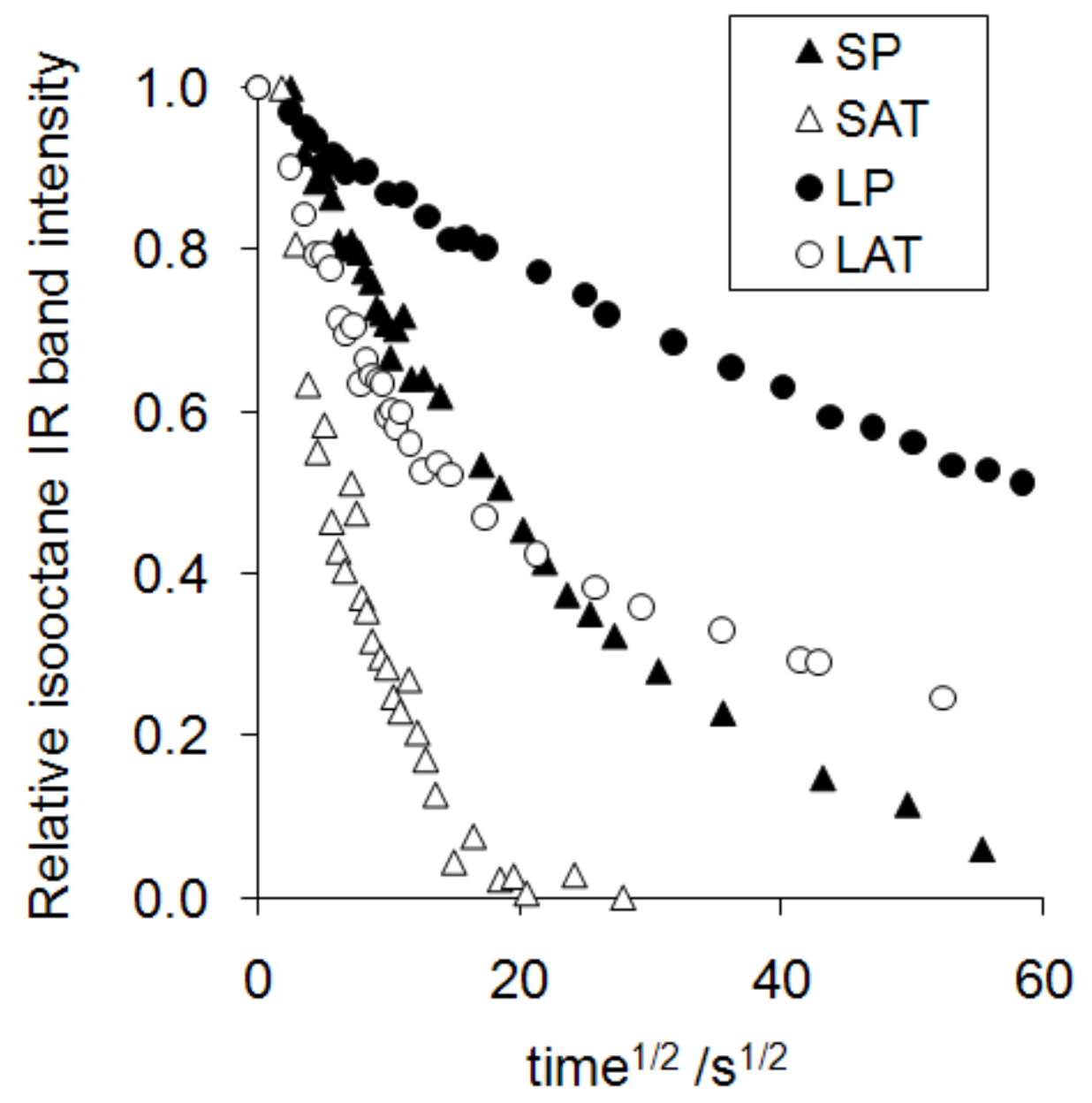


567 Figure 5.

568

569

570

571

572

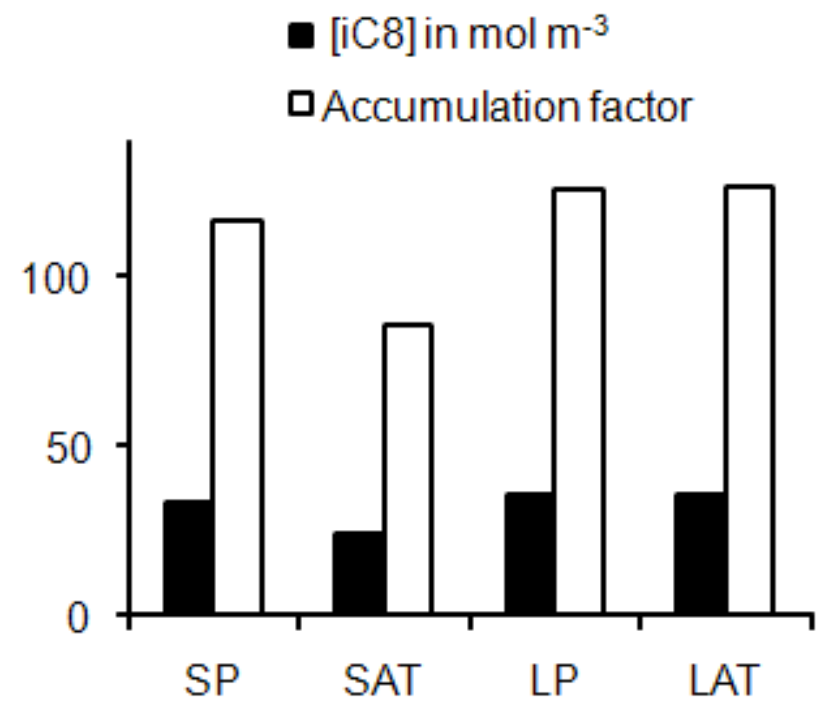

